\title{
Supporting student collaboration in online breakout rooms through interactive group activities
}

\author{
David Read*,1,2, Stephen M. Barnes ${ }^{1}$, Oliver Hughes ${ }^{1}$, Iveta Ivanova ${ }^{3}$, Annabelle Sessions ${ }^{1}$ and \\ Paul J. Wilson ${ }^{1}$
}

${ }^{1}$ School of Chemistry and ${ }^{2}$ Centre for Higher Education Practice, University of Southampton, Highfield, Southampton SO17 1BJ (UK)

${ }^{3}$ School of Physics, Kings College London, Strand Campus, Strand, London, WC2R 2LS.

*Corresponding Author: d.read@soton.ac.uk

Keywords: Blended learning; Online learning; Active learning; Peer learning; Group work

\begin{abstract}
Many instructors globally reported a lack of engagement in synchronous online sessions during the Covid-19 lockdowns. This article outlines the use of collaborative small group tasks mediated via breakout rooms in Teams during the 2020/21 academic year. The rationale for the activities, which are available for download, is described along with details of the evaluation of their impact. Key findings were that a majority of students reported enjoying the tasks and felt that they improved their learning during online sessions.
\end{abstract}

\section{Overview}

The global shift to online teaching in Spring 2020 as a result of the Covid-19 pandemic presented a range of challenges to educators in higher education (Nordmann et al., 2020). Moving lecture content online was relatively straightforward thanks to the widespread adoption of lecture capture and comfort with the technology, but it was much more difficult to replicate active and collaborative learning in an online setting (Mishra, Gupta \& Shree, 2020). This article outlines the development and evaluation of a series of collaborative tasks that students completed in groups assigned to breakout rooms in Microsoft Teams during the 2020/21 academic year.

\section{Context}

As discussed previously (Read, Watts, \& Wilson, 2016; Wright, Read, Hughes, \& Hyde, 2018), the Science Foundation Year (SFY) at the University of Southampton provides an entry route onto science degree programmes for students who do not have the required qualifications for direct entry, with a typical cohort size of 40-60. Prior to the pandemic, the SFY chemistry module featured 3 chemistry lectures per week and a workshop session (15-20 students) that included collaborative group activities as well as worksheet-based problem sets, with a staff member and two demonstrators present.

\section{Teaching in the first lockdown}

In Spring 2020, all lectures were made available as chunked recordings that incorporated interactive quiz questions and a 'talking head' video of the instructor alongside captured PowerPoint slides (Read, Barnes, \& Wilson, 2022) (full details were shared via a webinar: https://youtu.be/OYAXeeBPsls). During lockdown, no lab sessions took place, with students instead undertaking an assignment based on provided experimental data. In the absence of in-person workshops, students were provided with activity worksheets each week to complete independently. Demonstrator support was replaced by 'talking mark schemes' (Read, Barnes, Hyde \& Wright, 2019) that 
communicated the thought process behind each answer, supporting self-assessment by students. A one hour synchronous online session took place on Friday afternoons, in which students responded to multiple choice questions delivered via the Vevox voting system (www.vevox.com). Staff also addressed misconceptions and challenges commonly encountered by students in relation to the topic under study.

As widely reported by others (Jeffery \& Bauer, 2020), there was a lack of student interaction during synchronous online teaching, with cameras and microphones mostly turned off and little evidence of engagement beyond responding to in-session voting questions. Our informal evaluation of the student response to teaching during the first lockdown indicated that students were uncomfortable contributing in whole group sessions, with a common suggestion being the allocation of smaller groups to undertake collaborative tasks and discussion.

\section{Online breakout rooms}

The use of breakout rooms in online teaching had been explored by some educators prior to the pandemic. Chandler (2016) reported the successful application of breakout rooms, describing them as virtual spaces that are separate from the main 'room' and facilitate collaborative learning and interaction between students. Instructors can create multiple breakout rooms within which only those present can hear discussions and view the chat away from the gaze of the instructor. Tonsmann (2014) reported that participation in group problem-solving activities in breakout rooms was valuable in giving students the opportunity to learn from each other and that this could be more straightforward logistically than doing so in class.

As noted by Kuhn (2015), the outcomes of collaborative learning can be precarious and it is therefore important to carefully design a collaborative task and to prepare students appropriately. Such work can be time consuming, as noted by Baehr (2012) who found that preparing for online tutorials takes tutors up to 20 per cent longer than in-person sessions. Chandler (2016) suggested that breakout activities should be "easy and fun, rather than anything too challenging", with an example of a drag-and-drop activity being proposed. Saltz and Heckman (2020) investigated the use structured pair activities (SPA) in which students were provided with scripted role assignments that guided them in acting as the 'driver' or 'observer' as they worked in pairs on problems. Unsurprisingly, it was found that students in SPA breakout rooms achieved more than those working on unstructured activities. Chandler (2016) recommended making a list of any information that needs to be given to students prior to the activity to ensure nothing is missed out.

Chandler (2016) noted that tutors and students can have mixed experiences with breakout rooms, and may feel nervous when trying them for the first time. Yamagata-Lynch (2015) described breakout rooms as the aspect of online tuition that posed the most difficulty. She presented modifications to the way she facilitated small group work over time, such as allocating students to groups with more care, allocating students particular roles and providing a more structured framework for the time in breakout rooms. McDonald and Campbell (2012) argue that as well as familiarity with the technicalities of the online conferencing tool, tutors need opportunities to learn about effective approaches to facilitating online sessions and how to design effective activities.

\section{Breakout rooms in chemistry teaching during the pandemic}

Following the arrival of the pandemic, some instructors began to experiment with breakout rooms, making use of functionality in platforms such as Zoom and Blackboard Collaborate. In some early reports, students expressed a desire for more group work through the use of breakout rooms (Fung \& Lam, 2020; Perets et al., 2020). The use of structured breakout group activities in online conferences e.g. the MICER conference in June 2020 (Seery \& Flaherty, 2020) gave unseasoned colleagues the first-hand experience of the technology and further promoted the approach.

There are numerous reports of instructors using breakout rooms in synchronous online teaching during the pandemic. Jeffery and Bauer (2020) reported that students missed 
interacting with peers and suggested the routine use of breakout rooms to mitigate this deficiency. However, it was noted that some such opportunities were not productive (e.g. silent breakout rooms when students were asked to discuss a question), highlighting a need to explicitly discuss with students the importance of collaboration and how to do it well. Similarly, Petillion and McNeil (2020) reported that the use of breakout rooms in the online environment was not regarded by students as well-managed or supportive of learning, although the specifics of the approaches employed were not discussed.

Where students responded favourably to breakout rooms, there were some common themes. Van Heuvelen et al. (2020) found that breakout groups became more effective when more structure was provided and a group leader allocated to overcome hesitancy to speak up. Fung and Lam (2020) pre-assigned the groups, and also allocated a leader to take notes and log key points on Padlet, leading to high levels of engagement. In another example, Singhal (2020) assigned students a collaborative assignment, giving them a clear set of tasks and the motivation to complete them, leading to similar attainment outcomes to those achieved pre-pandemic. Wenzel (2020) employed a similar approach, with students working collaboratively on worksheet-based exercises, which was observed to support meaningful discussions about the subject matter. Nonetheless, students in this case indicated a preference for in-person teaching.

A particularly effective approach was the use of shared, editable files and documents as collaborative tools. Jamieson (2020) noted that a shared Google Doc or whiteboard could be created for groups to record their discussions and facilitate sharing in the main session. Fulfer et al. (2020) also provided Google Docs for each group, allowing the instructor to monitor each group's progress during the session and to enter breakout rooms where evidence of students' misconceptions was observed. Gemmel et al. (2020) provided students with collaborative tasks in Canvas alongside a Google Doc, and noted advantages in being able to include vivid colour and video files more easily than when delivering paper-based tasks in class. In this example, students were assigned specific roles in each group, and their work was monitored to identify when intervention was needed during the session.

\section{SFY breakout room activities}

In-person teaching (laboratory $3 \mathrm{hrs} / \mathrm{wk}$ and biology/chemistry/maths workshops $3 \times 1$ $\mathrm{hr} / \mathrm{wk}$ ) took place throughout 2020/21, apart from Jan - Mar 2021, when the UK was in a comprehensive lockdown. However, social distancing meant that collaborative group work was not possible. Active learning is a key feature of SFY workshops in normal times and group work enables peer interaction where stronger students support those who are struggling, providing benefits to both groups. The loss of group work also removed an opportunity for students to get to know their peers and this was a concern socially, particularly in view of the impact of the pandemic on student life. Hence our aims in making use of breakout rooms were to provide an opportunity for students work with their peers to improve their confidence in applying their learning, as well as providing an opportunity for them to interact meaningfully.

As reported previously, postgraduate teaching assistants (PGTAs) have played a key role in designing and evaluating activities they have created for the SFY programme (Read, Barnes, Harrison, Koramoah, \& Ivanova, 2017). A number of these active learning resources were adapted for use in breakout rooms during online synchronous workshop sessions (1 hour) running on Thursday afternoons throughout the year. A number of new activities were created to take advantage of the opportunities afforded by the technology. Each breakout room activity was made up of 2 - 4 tasks relating to that week's material. The first task was designed not to be too difficult, with the aim that all students would be able to complete it. Subsequent tasks tended to be more difficult to stretch those groups who were able to progress.

In most cases, shared, editable PowerPoint (PPT) files were created to host the activities, which included drag-and-drop exercises, diagrams to annotate and tables of text to fill in. A task that was repeated several times during the year involved naming organic compounds based on structures given on the slides. A list 


\begin{tabular}{|l|l|}
$\begin{array}{l}\text { Topic } \\
\text { Basic organic } \\
\text { nomenclature }\end{array}$ & $\begin{array}{l}\text { Greakout room activity description } \\
\text { a starter to be dragged under the correct structure. }\end{array}$ \\
\hline $\begin{array}{l}\text { Hess's cycle } \\
\text { Components of a cycle are laid out randomly to be rearranged into the correct } \\
\text { alignment by the group, allowing them to calculate } \Delta H .\end{array}$ \\
\hline $\begin{array}{l}\text { Catalytic } \\
\text { Hydrocarbons } \\
\text { and functional } \\
\text { groups }\end{array}$ & $\begin{array}{l}\text { Groups arrange steps into correct sequence and create a particle diagram to } \\
\text { illustrate the catalytic process. }\end{array}$ \\
\hline $\begin{array}{l}\text { Incomplete } \\
\text { mechanism }\end{array}$ & $\begin{array}{l}\text { Gromes (see Figure 1). } \\
\text { nams annotate an incomplete mechanism, explaining the steps and adding } \\
\text { missing intermediates. }\end{array}$ \\
\hline $\begin{array}{l}\text { Erroneous } \\
\text { mechanism }\end{array}$ & $\begin{array}{l}\text { Groups evaluate a mechanism that is riddled with errors and add annotations } \\
\text { stating what is wrong. }\end{array}$ \\
\hline $\begin{array}{l}\text { Spectroscopic } \\
\text { analysis }\end{array}$ & $\begin{array}{l}\text { Two-part activity involving i) prediction of MS, IR and }{ }^{1} \mathrm{H} \text { NMR spectra for a } \\
\text { given compound and ii) identification of compound based on spectral data. }\end{array}$ \\
\hline $\begin{array}{l}\text { Strong and weak } \\
\text { acids }\end{array}$ & $\begin{array}{l}\text { Groups use a PhET simulation to explore acids and bases at a particle level } \\
\text { (https://phet.colorado.edu/en/simulation/acid-base-solutions). }\end{array}$ \\
\hline $\begin{array}{l}\text { Aromatic } \\
\text { chemistry }\end{array}$ & $\begin{array}{l}\text { Incomplete concept map of organic reactions with cards which groups need to } \\
\text { sort and place correctly. }\end{array}$ \\
\hline
\end{tabular}

Table 1 Summary of chemistry-based breakout group activities created during 2020/21

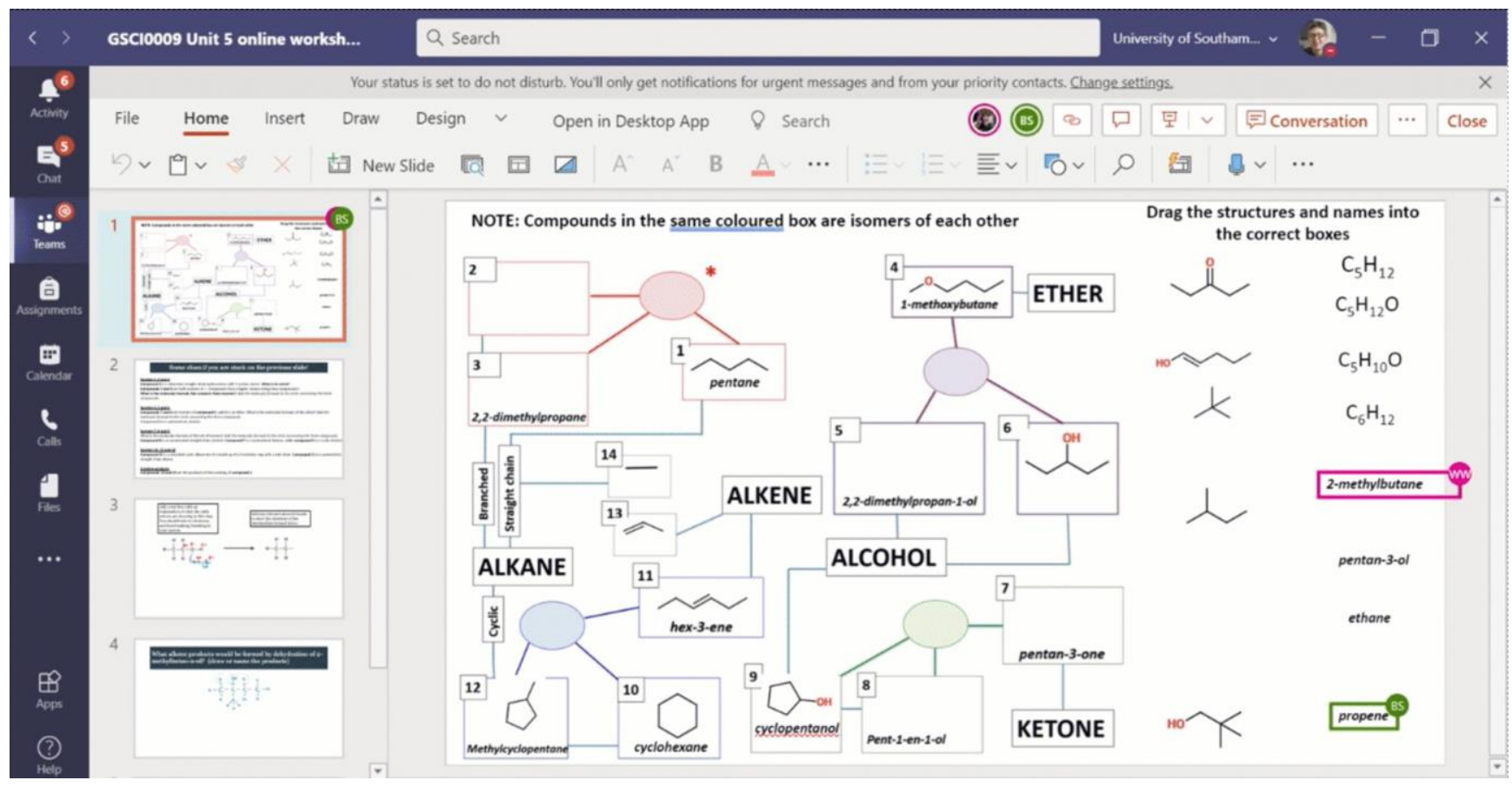

Figure 1 Example of an organic chemistry drag-and-drop activity being undertaken by students

of the activities created is given in Table 1. Similar collaborative activities were created as part of the 'Routes to Success' module, a skills module that runs throughout the year. These activities are outlined in Table 2 . Note that most of the shared files are available for download on the University of Southampton EdShare platform http://edshare.soton.ac.uk/20788/). 
Supporting student collaboration in online breakout rooms through interactive group activities

\begin{tabular}{|l|l|}
\hline $\begin{array}{l}\text { Topic } \\
\begin{array}{l}\text { Student- } \\
\text { generated } \\
\text { induction }\end{array}\end{array}$ & $\begin{array}{l}\text { Greakout room activity description } \\
\text { programme and submit them via the Q\&A feature in Vevox. }\end{array}$ \\
\hline $\begin{array}{l}\text { Academic } \\
\text { integrity }\end{array}$ & $\begin{array}{l}\text { Groups had } 15 \text { mins to generate a } ~ 1000 \text { word summary of a topic of their } \\
\text { choice, drawing on as many sources as possible. These were submitted to } \\
\text { Turnitin, allowing the demonstration of its originality check functionality. }\end{array}$ \\
\hline $\begin{array}{l}\text { Independent } \\
\text { learning }\end{array}$ & $\begin{array}{l}\text { Groups discuss a range of prompts (strengths and weaknesses exhibited by } \\
\text { students, challenges and risks associated with student freedom etc). }\end{array}$ \\
\hline $\begin{array}{l}\text { Extracting inform- } \\
\text { ation from text }\end{array}$ & $\begin{array}{l}\text { Groups read an article and write two questions to pose to other students after } \\
\text { the breakout rooms close. }\end{array}$ \\
\hline $\begin{array}{l}\text { Reflecting } \\
\text { practice }\end{array}$ & $\begin{array}{l}\text { Groups discuss prompts relating to motivation levels and then write tips for } \\
\text { incoming future students }\end{array}$ \\
\hline $\begin{array}{l}\text { Presentation } \\
\text { skills }\end{array}$ & $\begin{array}{l}\text { i) Groups review two presentations and identify good/bad features ii) groups } \\
\text { identify the different stages in planning a presentation iii) groups critique slides } \\
\text { created by previous students }\end{array}$ \\
\hline
\end{tabular}

Table 2 Summary of skills-based breakout group activities created during 2020/21

\section{Instructor reflections}

While it is undoubtedly the case that there is no substitute for in-person group work and collaboration, our experience was that there is also a place for similar activity being undertaken in an online format. If nothing else, it is likely that there will be increased online working in all workplaces in future and it is therefore important that students develop the requisite skills. The use of collaborative documents appeared to be effective, with such activities providing students with a framework for their interaction and a clear goal arising from the problem under consideration. Although group leaders were not assigned, it was evident that many groups found their own dynamic and benefits arose from keeping students in the same groupings week-onweek, although some students had different views. It was also evident that a number of students rarely engaged in breakout tasks, often citing technical issues, and in later sessions we encouraged those students to work on the same tasks individually.

The ability to monitor each group's work by viewing their progress on the shared PPT slides was a key benefit. In most sessions, one staff member and two undergraduate teaching assistants (UGTAs) supervised 8 or 9 breakout groups of up to 4 students, each monitoring 2 or 3 groups. It was possible to enter rooms where activity was slow or incorrect answers were given. Groups were instructed to send a chat message to the instructor (formulated as @david) if they needed assistance. On-screen annotation was used to add feedback, occasionally during breakout sessions but most often after the session. The apparent benefits observed prompted a provisional evaluation, undertaken by an undergraduate project student (AS).

\section{Evaluation}

A survey was created, made up of 10 Likertstyle prompts and 4 open response questions. The survey was piloted with 2 students resulting in some minor modifications to the wording of questions and prompts, and ethical approval was obtained via the University's ERGO system. The link to the survey (a Microsoft Form) was sent out to all 37 students on the programme just before Christmas with a reminder following in January. In total, 16 responses were collected, representing $43 \%$ of the cohort. Although this is a reasonable response rate for a survey of this nature, it means that caveats should be applied to the interpretation of the data.

\section{Responses to Likert-style prompts}

A summary of students' responses is presented in Figure 2. It is evident that the students who responded felt positive about the use of breakout rooms. Although enjoyment is not typically an educational aim, we felt this was important in view of the circumstances of the year, and it is gratifying that most respondents enjoyed the activities. It is clear that the ability to connect and share ideas was 
Supporting student collaboration in online breakout rooms through interactive group activities

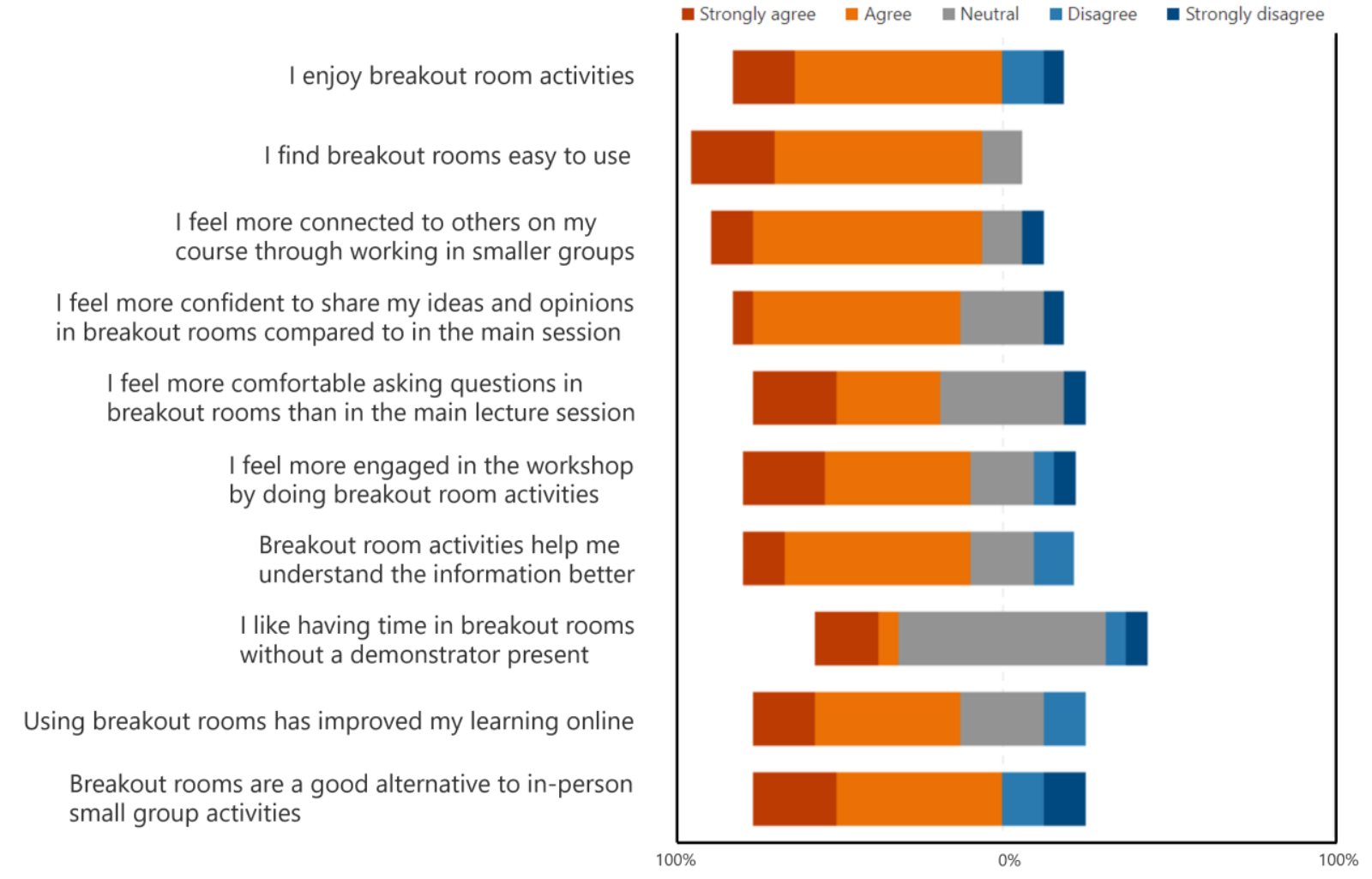

Figure 2 Summary of student responses to Likert-style prompts

valued by students, and they felt more engaged and that they understood information better as a result of participating. It is notable that a majority of respondents had a neutral view of the statement 'I like having time in breakout rooms without a demonstrator', indicating that many were in two minds; in the absence of a demonstrator, the room may feel more like a safe space for open thought, whereas the presence of a demonstrator provides a 'guide on the side' to support the activity. Finally, majorities of students were in agreement with statements about breakout rooms improving learning and being a good alternative to in-person activities, suggesting that this had been an appropriate approach to take when teaching in such circumstances.

\section{Data from open response questions}

The survey also contained 4 open response questions:

1) What do you think are the benefits of breakout rooms?

2) What do you like about using breakout rooms during workshops?

3) What do you dislike about using breakout rooms?
4) What would you change about the way breakout rooms have been used in this module?

Students' responses to these questions were pooled in Excel and subjected to thematic analysis (Braun \& Clarke, 2006) using a method described by Bree and Gallagher (2016). The resulting themes and illustrative quotes are listed in Table 3.

In line with the Likert responses, thematic analysis largely revealed positive comments in relation to breakout rooms, although again it should be noted that this is based on a $43 \%$ survey response rate. The data provides some evidence that the aims of the initiative have been achieved in that students report a number of benefits in relation to application of learning, social interaction and collaboration, in line with earlier findings by Chandler (2016) and Saltz (2020). Furthermore, some students reported that their understanding and engagement level had increased as a result.

Where comments were more negative, students cited the impact of technical issues and the lack of participation by some of their 
Supporting student collaboration in online breakout rooms through interactive group activities

\begin{tabular}{|c|c|}
\hline Theme & Illustrative quotes \\
\hline $\begin{array}{l}\text { Application of } \\
\text { learning }\end{array}$ & $\begin{array}{c}\text { "They are beneficial because it allows students to put in practice the knowledge } \\
\text { they've gained watching lectures/reading the textbook" } \\
\text { "It's a good way to test your understanding" }\end{array}$ \\
\hline Comfort & $\begin{array}{c}\text { "It is done in a "safe" space, without the professor and with less people than a } \\
\text { normal classroom, so it's easier for students to engage" } \\
\text { "I feel more comfortable and willing to interact with my peers" }\end{array}$ \\
\hline $\begin{array}{l}\text { Social } \\
\text { interaction with } \\
\text { peers }\end{array}$ & $\begin{array}{c}\text { "They allow us to bond with students from the class" } \\
\text { "The fact we can interact with other people on our course which we haven't } \\
\text { been able to do due to COVID" }\end{array}$ \\
\hline Collaboration & $\begin{array}{c}\text { "It also shows students their peers' way of working which can be helpful for } \\
\text { other students that may struggle with a specific topic" } \\
\text { "We can talk about the questions and share our idea" }\end{array}$ \\
\hline $\begin{array}{r}\text { Incre } \\
\text { unders }\end{array}$ & $\begin{array}{l}\text { "It helps me fully understand some topics that I may have been unsure on" } \\
\text { "Help understanding" }\end{array}$ \\
\hline $\begin{array}{l}\text { Increased } \\
\text { engagement }\end{array}$ & $\begin{array}{c}\text { "More active and engaging than just listening" } \\
\text { "It makes learning more active and requires students to be constantly engaged } \\
\text { with the teacher and the tasks" }\end{array}$ \\
\hline $\begin{array}{l}\text { Good alternative } \\
\text { to in-person }\end{array}$ & $\begin{array}{l}\text { "They are useful alternative to in person lessons" } \\
\text { "It helps to make the online sessions closer to that of normal lessons" }\end{array}$ \\
\hline $\begin{array}{l}\text { Liking for } \\
\text { breakout rooms }\end{array}$ & $\begin{array}{l}\text { "Overall they are helpful and effective" } \\
\text { "I think using breakout rooms is positive" } \\
\text { "To be honest, I really like breakout rooms" }\end{array}$ \\
\hline Technical issues & $\begin{array}{c}\text { "Sometimes I just can't actually get into the breakout room but that's more of a } \\
\text { technical issue" } \\
\text { "I don't really like to use my phone to answer questions because the screen is } \\
\text { so small" }\end{array}$ \\
\hline $\begin{array}{l}\text { Lack of parti } \\
\text { ation by oth }\end{array}$ & $\begin{array}{c}\text { "I find it hard when people don't engage" } \\
\text { "I also dislike that some people within the breakout rooms do not contribute } \\
\text { towards work" }\end{array}$ \\
\hline $\begin{array}{l}\text { Always } u \\
\text { same } p\end{array}$ & $\begin{array}{c}\text { "Most of the time, lecturers place us in the same group which I dislike as it } \\
\text { doesn't give me a chance to meet other people" } \\
\text { "Sometimes, l'd like if we were able to choose the people we are in groups } \\
\text { with" }\end{array}$ \\
\hline
\end{tabular}

Table 3 Themes identified in students' responses to open response questions

peers. While students tended to be kept in the same groups for multiple sessions, some reported that they would prefer to be in breakout groups with different students. It was noted that some students may not have contributed to discussions because they were uncomfortable doing so. Another point made by some was that it was problematic if cameras were off. Although students were encouraged to have cameras and microphones on throughout the breakout tasks, more could have been done to make sure this happened in practice. These points show that further work is needed to identify the best ways of grouping students for such activities and how best to begin each activity in a positive, proactive manner.

\section{Future work}

While there has been a move back to more inperson teaching in $2021 / 22$, online workshops alongside in-person sessions to increase contact time and to add variety to the delivery of teaching. This will enable us to refine the resources created this year and explore modifcations to the approach that might extend the benefits of using breakout rooms. The 
findings described herein have prompted the following planned changes:

- Work with students to identify effective ways of grouping them, drawing on their experiences of collaborating during in-person sessions throughout the year.

- Introduce more ice-breaker activities at the start of the year to ensure that students are more comfortable having cameras and microphones on in breakout rooms.

- Give students the opportunity to request a change of group in a way that avoids confrontation with peers.

There is much scope for research in this area, which could explore the benefits and disadvantages of group work in virtual breakout rooms in comparison to in-person activity. It would also be interesting to explore the nature of discourse that takes place in breakout rooms and how it differs from that occurring in an inperson session. Such work could shed light on the best ways of designing and running activities that will enhance learning and ensure that students develop digital transferrable skills that will benefit them in their future careers.

\section{References}

Baehr, C. (2012). Incorporating user appropriation, media richness, and collaborative knowledge sharing into blended e-learning training tutorial. IEEE Transactions on Professional Communication, 55(2), 175184. DOI: 10.1109/TPC.2012.2190346

Braun, V. \& Clarke, V. (2006). Using thematic analysis in psychology. Qualitative research in psychology, 3(2), 77-101. DOI: 10.1037/13620-004

Bree, R.T., \& Gallagher, G. (2016). Using Microsoft Excel to code and thematically analyse qualitative data: a simple, costeffective approach. All Ireland Journal of Higher Education, 8(2). https://tinyurl.com/rzr25u3t

Chandler, K. (2016). Using breakout rooms in synchronous online tutorials. Journal of Perspectives in Applied Academic Practice, 4(3), 16-23. DOI: 10.14297/jpaap.v4i3.216
Fulfer, K D., Wachter, E., Muzyka, J.L., Demoranville, L.T., Fieberg, J.E., Haile, J.D., Scott, D., Song, Y., Workman, J.M. \& Young, K.J. (2020). I\#StayCentred: Maintaining Personal Education at Centre College During COVID-19. Journal of Chemical Education, 97(9), 2783-2787. DOI: acs.jchemed.0c00726

Fung, F.M., \& Lam, Y. (2020). How COVID-19 Disrupted Our "Flipped" Freshman Organic Chemistry Course: Insights Gained from Singapore. Journal of Chemical Education, 97(9), 2573-2580. DOI: acs.jchemed.0c00590

Gemmel, P.M., Goetz, M.K., James, N.M., Jesse, K.A. \& Ratliff, B.J. (2020). Collaborative Learning in Chemistry: Impact of COVID-19. Journal of Chemical Education, 97(9), 28992904. DOI: acs.jchemed.0c00713

Jamieson, M.V. (2020). Keeping a Learning Community and Academic Integrity Intact after a Mid-Term Shift to Online Learning in Chemical Engineering Design During the COVID-19 Pandemic. Journal of Chemical Education, $\quad 97(9)$, 2768-2772. DOI: 10.1021/acs.jchemed.0c00785

Jeffery, K.A. \& Bauer,C. F. (2020). Students' Responses to Emergency Remote Online Teaching Reveal Critical Factors for All Teaching. Journal of Chemical Education, 97(9), 2472-2485. DOI: acs.jchemed.0c00736

Kuhn, D. (2015). Thinking together and alone. Educational researcher, Educational Researcher, 44(1), 46-53. DOI: $10.3102 / 0013189 \times 15569530$

Macdonald, J. \& Campbell, A. (2012). Demonstrating online teaching in the disciplines. A systematic approach to activity design for online synchronous tuition. British Journal of Educational Technology, 43(6), 883891. DOI: 10.3102/0013189X15569530

Mishra, L., Gupta, T. \& Shree, A. (2020). Online teaching-learning in higher education during lockdown period of COVID-19 pandemic. International Journal of Educational Research Open, 1, 100012. DOI: 10.1016/j.ijedro.2020.10001 
Supporting student collaboration in online breakout rooms through interactive group activities

Nordmann, E., Horlin, C., Hutchison, J., Murray, J.-A., Robson, L., Seery, M.K., \& MacKay, J.R.D. (2020). Ten simple rules for supporting a temporary online pivot in higher education. PLOS Computational Biology, 16(10), e1008242. DOI: 10.1371/journal.pcbi. 1008242

Perets, E.A., Chabeda, D., Gong, A.Z., Huang, X., Fung, T.S., Ng, K.Y., Bathgate, M. \& Yan, E.C.Y. (2020). Impact of the Emergency Transition to Remote Teaching on Student Engagement in a Non-STEM Undergraduate Chemistry Course in the Time of COVID-19. Journal of Chemical Education, 97(9), 24392447. DOI: 10.1021/acs.jchemed.0c00879

Petillion, R.J. \& McNeil, W. S. (2020). Student Experiences of Emergency Remote Teaching: Impacts of Instructor Practice on Student Learning, Engagement, and Well-Being. Journal of Chemical Education, 97(9), 24862493.

https://doi:10.1021/acs.jchemed.0c00733

Read, D., Barnes, S.M., Harrison, C.K., Koramoah, R. \& Ivanova, I. (2017). Utilising graduate teaching assistants to implement active learning at university level. New Directions in the Teaching of Physical Sciences(12). 10.29311/ndtps.v0i12.2367

Read, D., Barnes, S. M., Hyde, J., \& Wright, J. S. (2019). Nurturing reflection in science foundation year undergraduate students. Teaching Chemistry in Higher Education: A Festschrift in Honour of Professor Tina Overton, 23-37. https://tinyurl.com/sx6mvtkb

Read, D., Watts, J.K., \& Wilson, T.J. (2016). Partial flipping to support learning in lectures. In The Flipped Classroom Volume 2: Results from Practice (pp. 55-79): ACS Publications. https://10.1021/bk-2016-1228.ch004

Read, D., Barnes, S.M. \& Wilson, P.J. (2022). Online lecture recordings; Lessons learned from lockdown. New Directions in the Teaching of Physical Sciences, 16. DOI: 10.29311/ndtps.v0i17.3950

Saltz, J. \& Heckman, R. (2020). Using Structured Pair Activities in a Distributed
Online Breakout Room. Online Learning, 24(1), 227-244. https://tinyurl.com/3n4af3u7

Seery, M.K. \& Flaherty, A.A. (2020). Ten tips for running an online conference. Journal of Chemical Education, 97(9), 2779-2782. DOI: 10.1021/acs.jchemed.0c00833

Singhal, M.K. (2020). Facilitating virtual medicinal chemistry active learning assignments using advanced Zoom features during COVID-19 campus closure. Journal of Chemical Education, 97(9), 2711-2714. DOI: 10.1021/acs.jchemed.0c0083

Tonsmann, G. (2014). A Study of the Effectiveness of Blackboard Collaborate for Conducting Synchronous Courses at Multiple Locations. InSight: A Journal of Scholarly Teaching, 9 , 54-63. http://files.eric.ed.gov/fulltext/EJ1035850.pdF

Van Heuvelen, K.M., Daub, G.W. \& Van Ryswyk, H. (2020). Emergency Remote Instruction during the COVID-19 Pandemic Reshapes Collaborative Learning in General Chemistry. Journal of Chemical Education, 97(9), 2884-2888. DOI: 10.1021/acs.jchemed.0c00691

Wenzel, T. (2020). Collaborative Group Learning in Remotely Taught Analytical Chemistry Courses. Journal of Chemical Education, 97(9), 2715-2718. DOI: 10.1021/acs.jchemed.0c00520

Wright, J.S., Read, D., Hughes, O. \& Hyde, J. (2018). Tracking and assessing practical chemistry skills development: practical skills portfolios. New Directions in the Teaching of Physical Sciences, 13(1). DOI: 10.29311/ndtps.v0i13.2905

Yamagata-Lynch, L.C., Do, J., Skutnik, A.L., Thompson, D.J., Stephens, A.F., \& Tays, C.A. (2015). Design lessons about participatory self-directed online learning in a graduate-level instructional technology course. Open Learning: The Journal of Open, Distance and e-Learning, 30(2), 178-189. DOI: $10.1080 / 02680513.2015 .1071244$ 


\section{Appendix:}
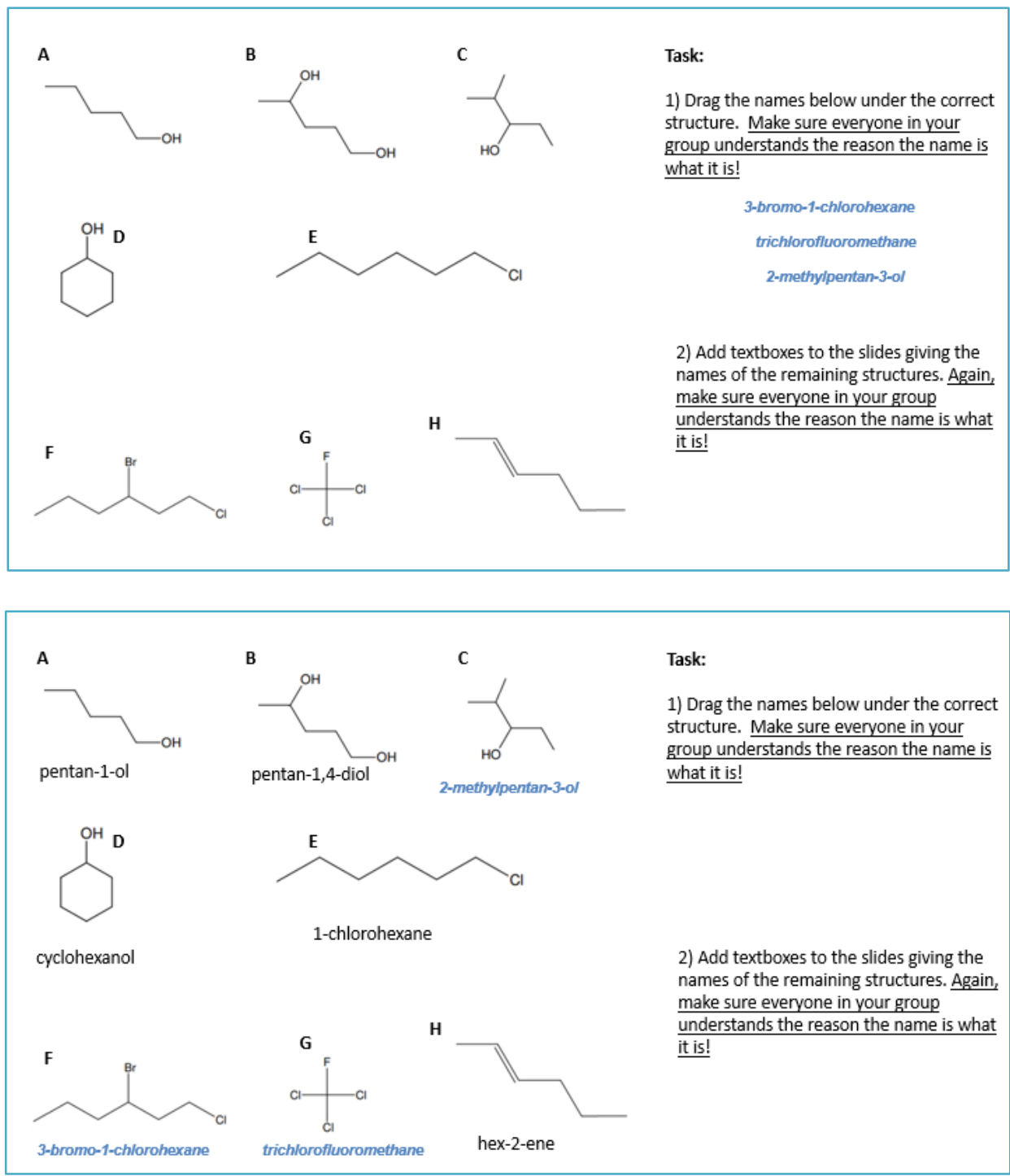

In this problem, you can calculate a value for the enthalpy change of formation of butane using a Hess cycle and the enthalpy changes of combustion of butane and its elements.

i) Rearrange the images below to create the equation representing the formation of 1 mole of butane from its elements in their standard states.

ii) Rearrange the remaining images to create an enthalpy (Hess) cycle to show the relationship between the formation of butane from carbon and hydrogen to the combustion of these elements to give carbon dioxide and water

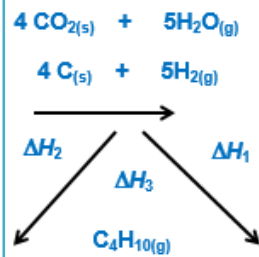

\begin{tabular}{|c|c|}
\hline$\Delta H_{c}^{\circ}(\mathrm{C})$ & $-393 \mathrm{~kJ} \mathrm{~mol}^{-1}$ \\
\hline$\Delta H_{c}{ }^{\circ}\left(\mathrm{H}_{2}\right)$ & $-286 \mathrm{~kJ} \mathrm{~mol}^{-1}$ \\
\hline$\Delta H_{\mathrm{c}}{ }^{\circ}\left(\mathrm{C}_{4} \mathrm{H}_{10}\right)$ & $-2877 \mathrm{~kJ} \mathrm{~mol}^{-1}$ \\
\hline
\end{tabular}

Butane: $\mathrm{C}_{4} \mathrm{H}_{10}$

Use your enthalpy cycle to calculate a value for the standard enthalpy change of formation of butane.

$$
\Delta H_{1}=\Delta H_{2}-\Delta H_{3}
$$


Supporting student collaboration in online breakout rooms through interactive group activities

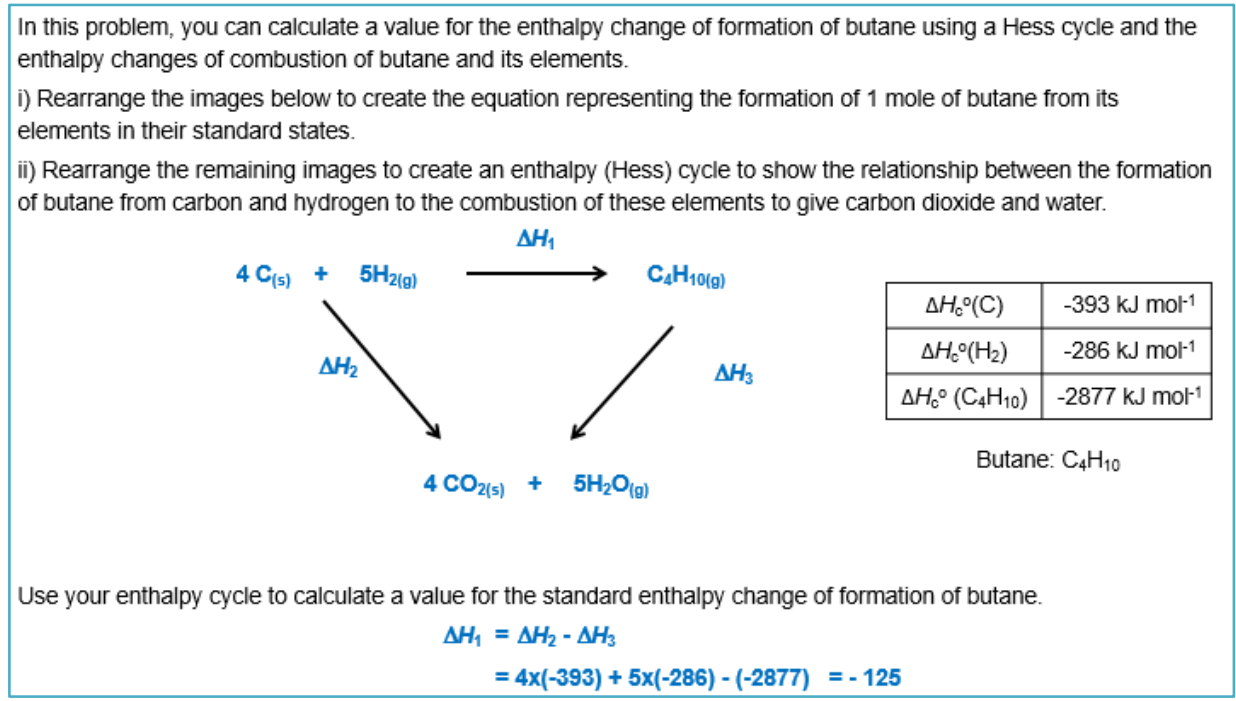

Place the following statements in chronological order to describe what happens in a catalytic converter:

The bonds within the pollutant molecules are weakened

This lowers the activation energy for the reactions that subsequently take place

The catalyst is regenerated and can go onto catalyse further reactions

The product molecules are desorbed and leave the catalytic converter

Pollutant molecules enter the catalytic converter from the engine

Bonds then break in the reactants and new bonds are made in the products

Pollutant molecules are adsorbed onto the catalyst surface

Place the following statements in chronological order to describe what happens in a catalytic converter:

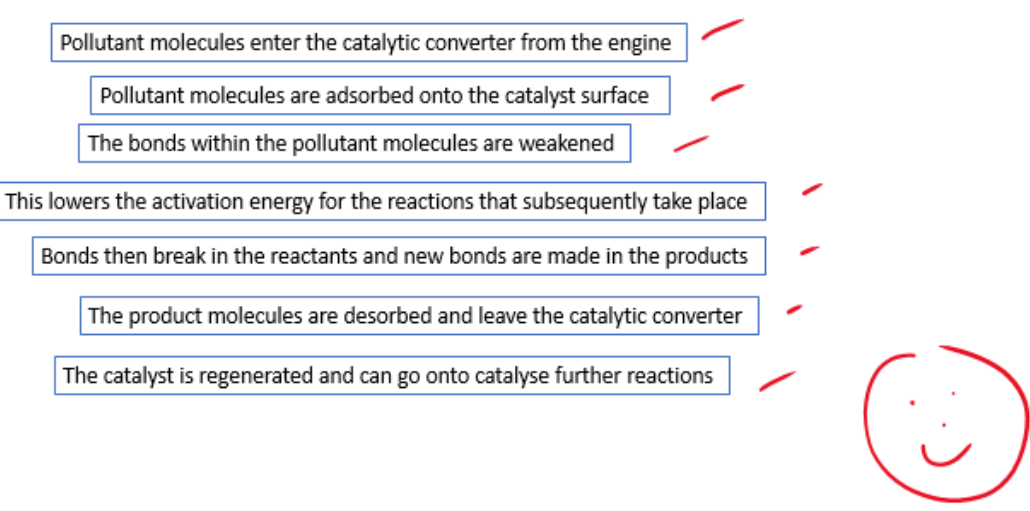


Supporting student collaboration in online breakout rooms through interactive group activities
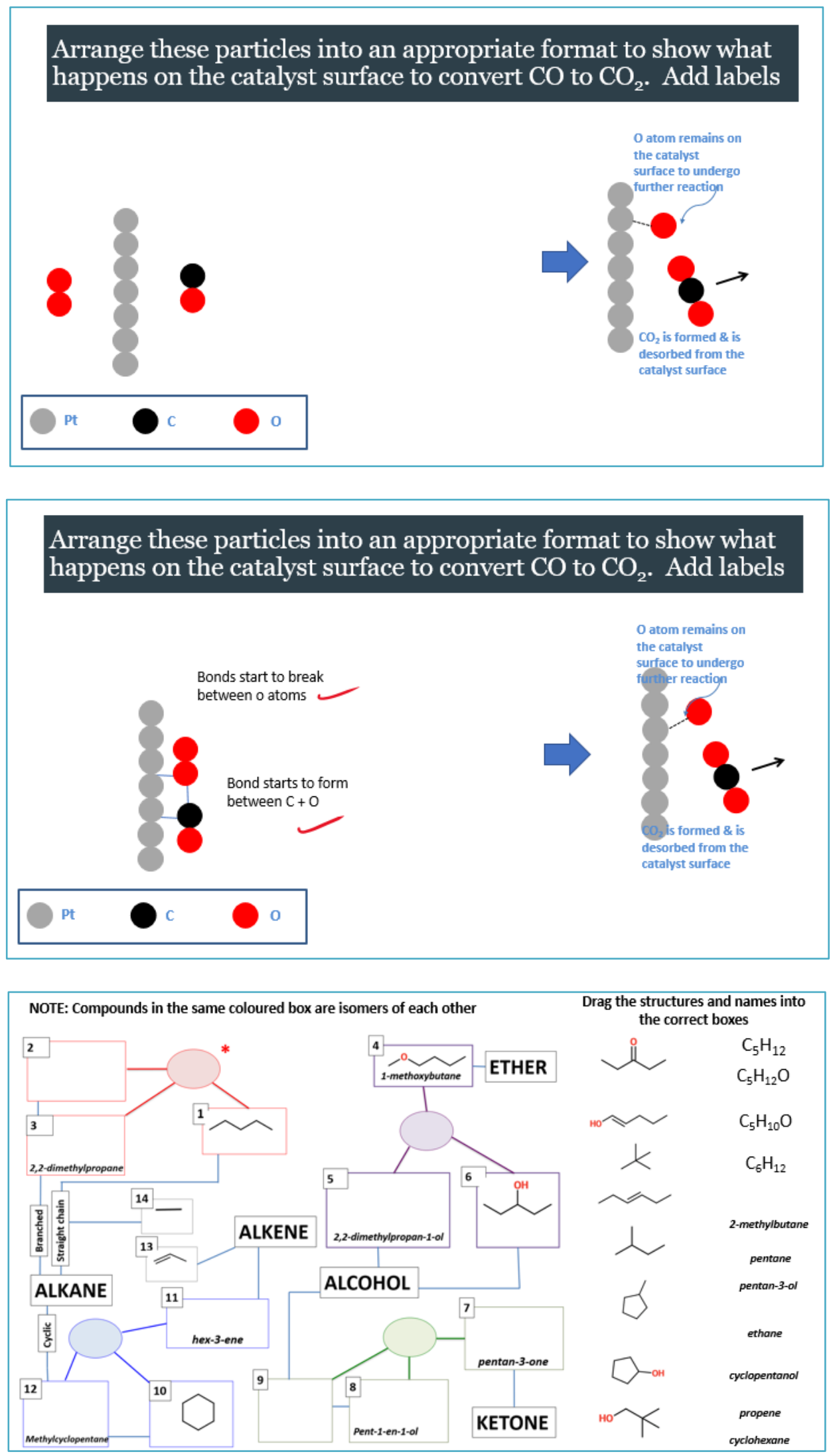
Supporting student collaboration in online breakout rooms through interactive group activities
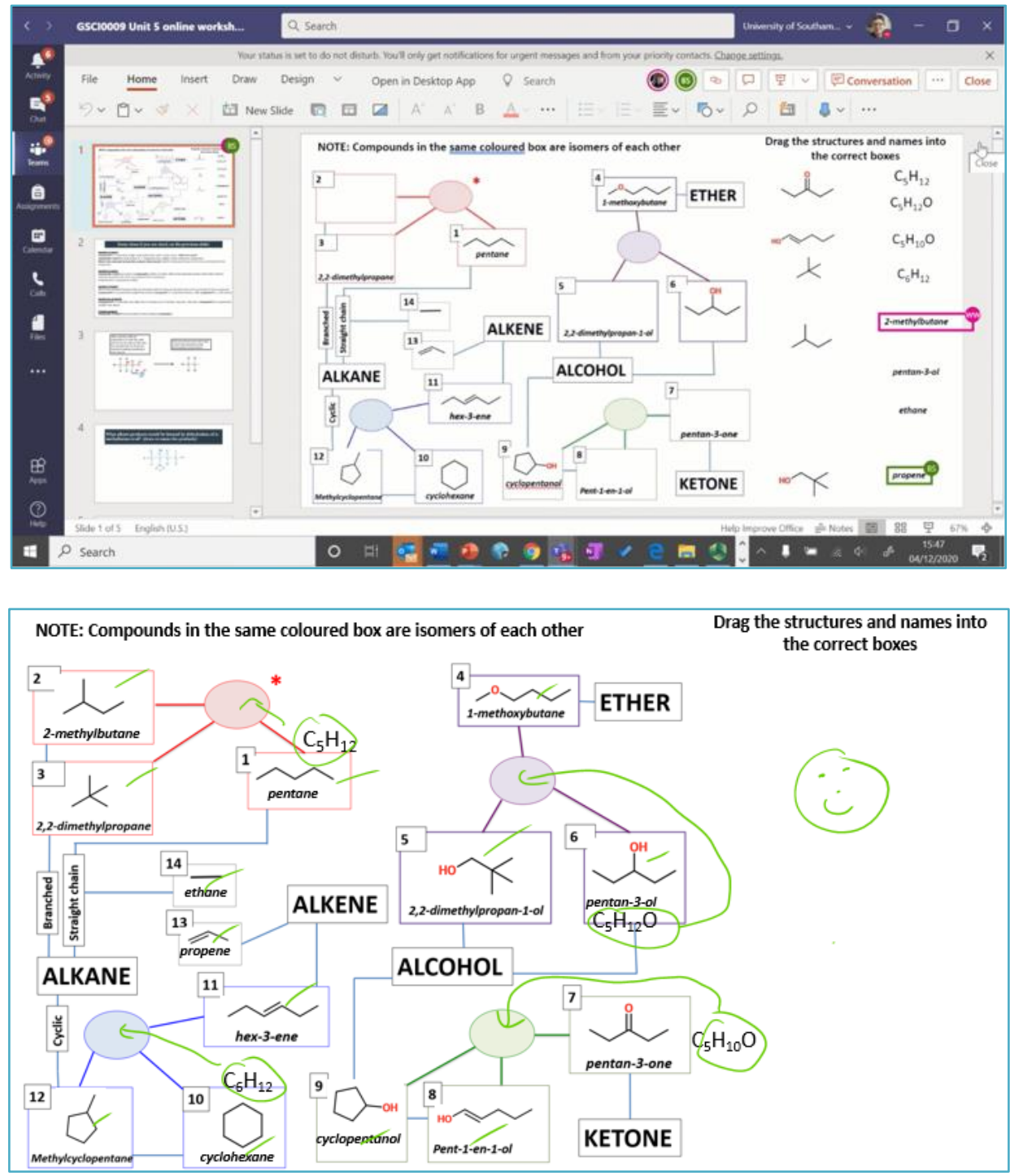

$$
\begin{aligned}
& \begin{array}{l}
\text { Add a text box with an } \\
\text { explanation of what the curly } \\
\text { arrows are showing in this step. } \\
\text { You should refer to electrons, } \\
\text { and bond making/breaking in } \\
\text { your answer. }
\end{array} \\
& \text { to show the structure of the } \\
& \text { intermediate formed below: }
\end{aligned}
$$

Add any relevant atoms \& bonds 
Supporting student collaboration in online breakout rooms through interactive group activities

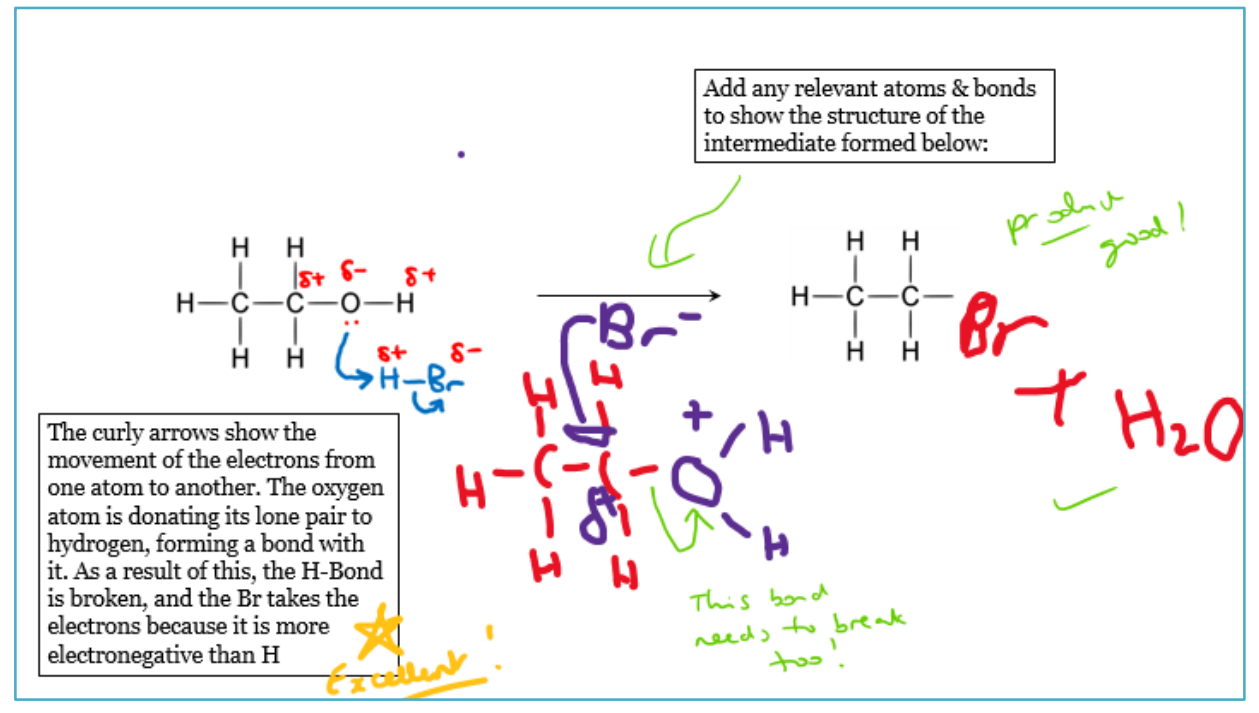

Identify the errors in the mechanism shown and add labels to explain what is wrong with the answers

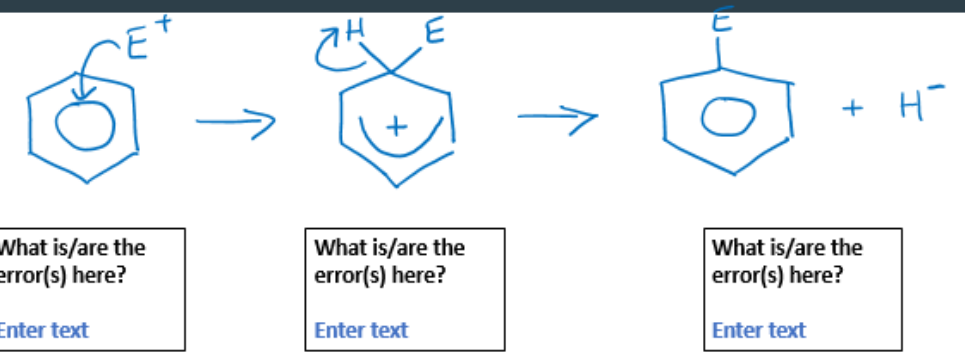

Identify the errors in the mechanism shown and add labels to explain what is wrong with the answers

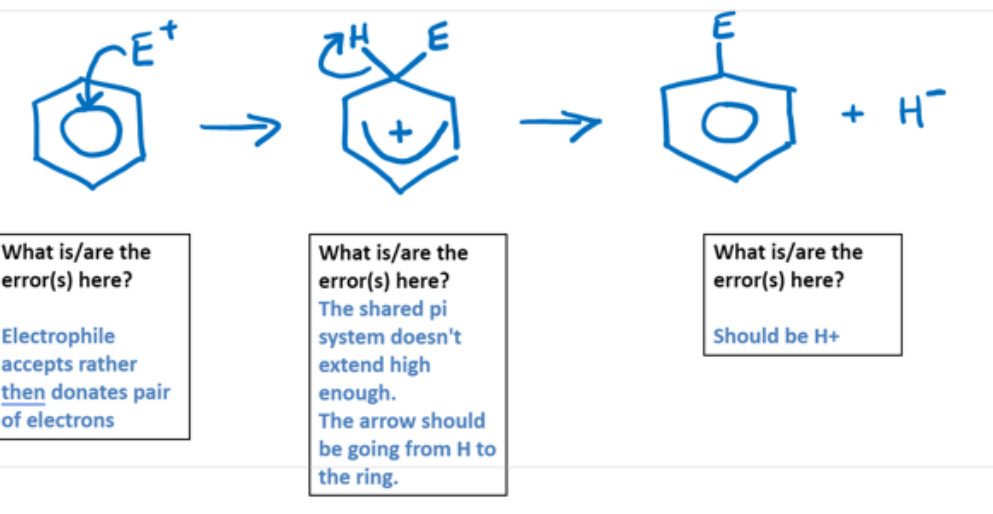


Supporting student collaboration in online breakout rooms through interactive group activities

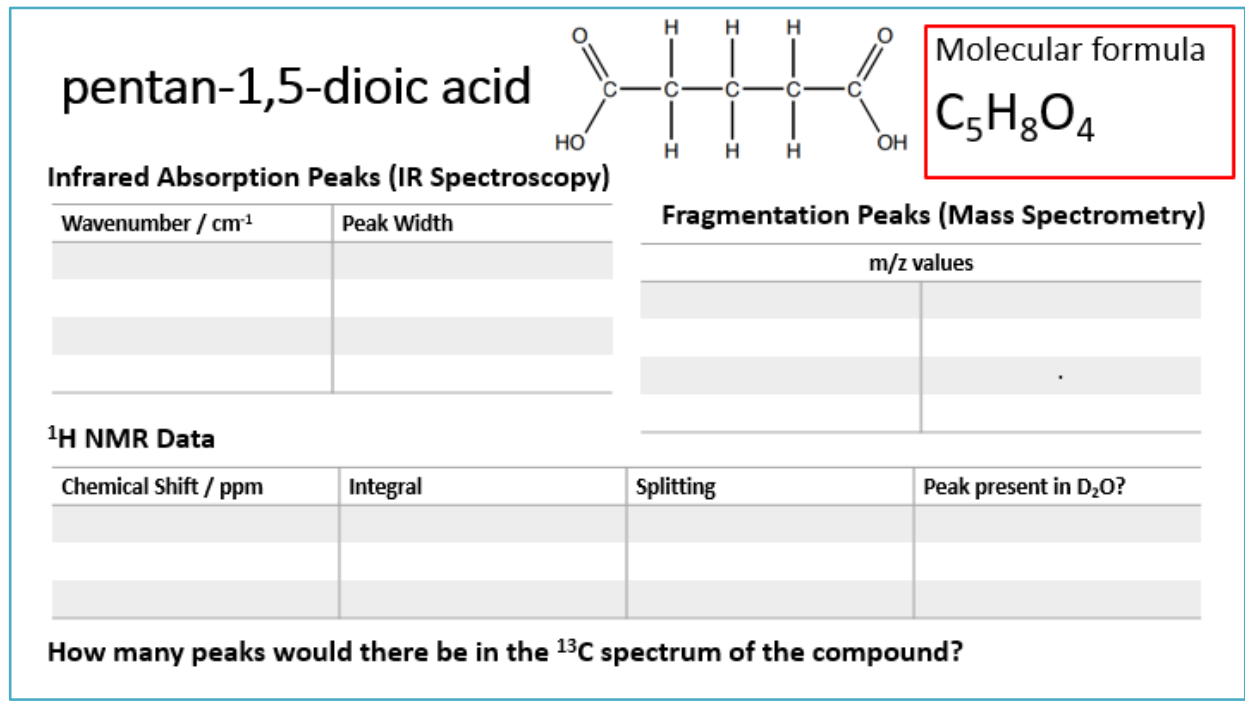

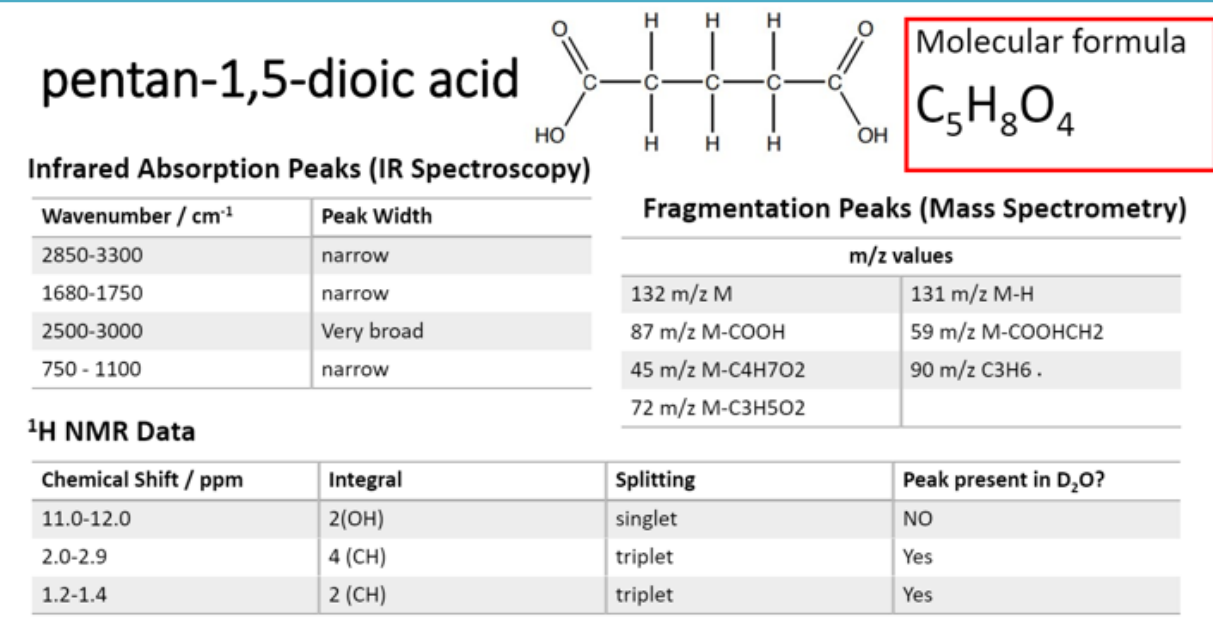

How many peaks would there be in the ${ }^{13} \mathrm{C}$ spectrum of the compound? 3 ?

Part 1 - On the introduction tab, explore the different solutions, views and tools, then answer the questions below

Q1) a) What is the difference between a strong acid and a weak acid?

[replace this text with your answer]

Q1) b) How is this shown visually in the simulation? (In your answer, refer to the different types of particles present in the solution)

[replace this text with your answer]

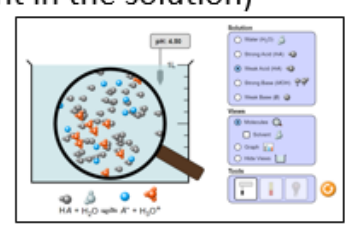


Supporting student collaboration in online breakout rooms through interactive group activities

Part 1 - On the introduction tab, explore the different solutions, views and tools, then answer the questions below

Q1) a) What is the difference between a strong acid and a weak acid?

Strong acid fully dissociates, weak acid only partially dissociates.

Q1) b) How is this shown visually in the simulation? (In your answer, refer to the different types of particles present in the solution)

With strong acid, there's a higher concentration of CA and CB (HA disappears from the products)

Have a discussion about the points below and add some notes about what you discuss. Spend $\sim 4$ mins on each point.

1) What are the strengths and weaknesses that students typically display? (think broadly)

Type your answer here by replacing this text

2) Explore ways in which a student might go about developing their strengths and weaknesses whilst at University and and give some of your suggestions below.

Type your answer here by replacing this text

Have a discussion about the points below and add some notes about what you discuss. Spend $\sim 4$ mins on each point.

1) What are the strengths and weaknesses that students typically display? (think broadly)

Weaknesses= time management.

Lack of motivation

Being too social interfers with study time.

Many distractions.

Strengths = Good when working in a team, determination to do well.

2) Explore ways in which a student might go about developing their strengths and weaknesses whilst at University and and give some of your suggestions below.

Make time table to improve time management skills.

Work with other students to motivation. 
Supporting student collaboration in online breakout rooms through interactive group activities

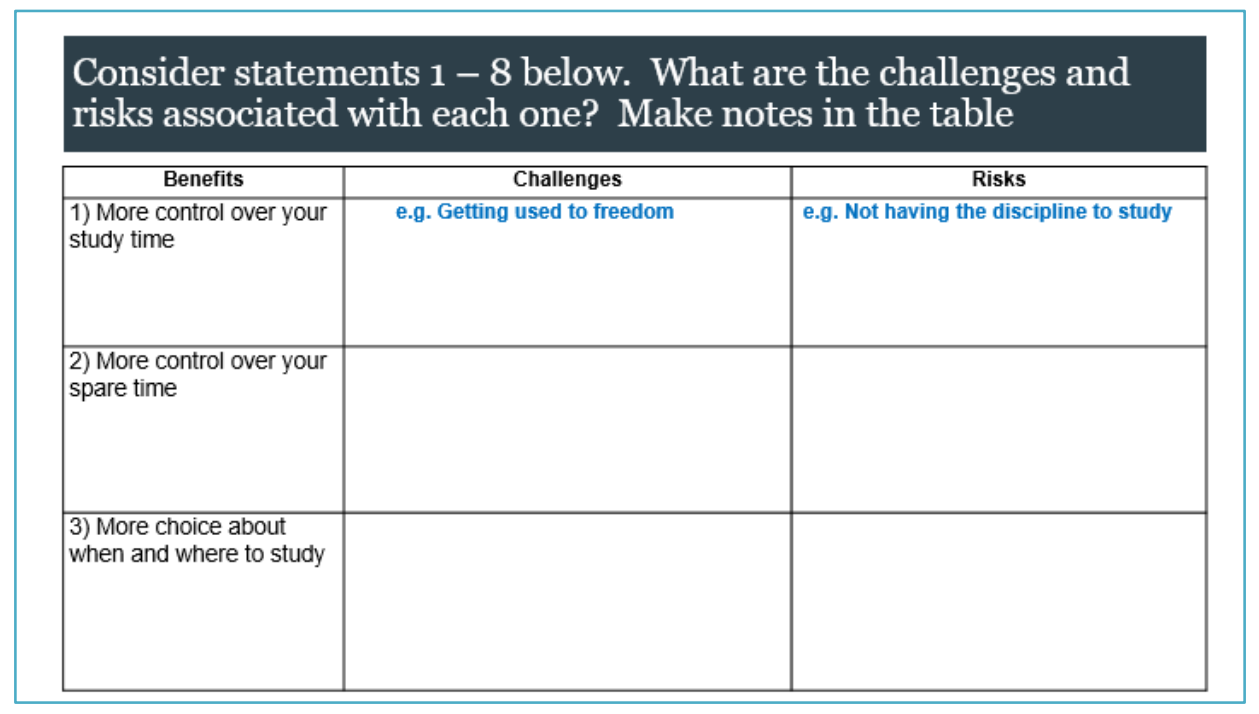

Consider statements $1-8$ below. What are the challenges and risks associated with each one? Make notes in the table

\begin{tabular}{|l|l|l|}
\hline \multicolumn{1}{|c|}{ Benefits } & \multicolumn{1}{|c|}{ Challenges } & \multicolumn{1}{c|}{ Risks } \\
\hline $\begin{array}{l}\text { 1) More control over your } \\
\text { study time }\end{array}$ & $\begin{array}{l}\text { e.g. Getting used to freedom } \\
\text { 1) Its all online this year }\end{array}$ & $\begin{array}{l}\text { e.g. Not having the discipline to study } \\
\text { 1) Lectures are pre-recorded can be } \\
\text { watched last minute= rushed = less } \\
\text { information retained. }\end{array}$ \\
\hline $\begin{array}{l}\text { 2) More control over your } \\
\text { spare time }\end{array}$ & $\begin{array}{l}\text { Getting too relaxed when you have } \\
\text { spare time. }\end{array}$ & $\begin{array}{l}\text { May lose track of time easily and find it } \\
\text { difficult to get back on track. }\end{array}$ \\
\hline $\begin{array}{l}\text { 3) More choice about } \\
\text { when and where to study }\end{array}$ & $\begin{array}{l}\text { Library has to be booked } \\
\text { Depends on individuals motivation } \\
\text { levels. }\end{array}$ & $\begin{array}{l}\text { Catching covid and your less likely to } \\
\text { go if you have to book.\# } \\
\text { Less work may be done then in a normal } \\
\text { year due to a lack of a timetable. }\end{array}$ \\
\hline
\end{tabular}

\section{Let's get started...}

Discuss the following questions in your groups:

As you work through Semester 2, how would you describe your levels of motivation? Are you always highly motivated? Has anything changed during the year?

During the foundation year has your level of motivation varied, and if so, what are the likely triggers for that variation?

Looking ahead, how will you maintain high levels of motivation in order to achieve your ambitions? 
Supporting student collaboration in online breakout rooms through interactive group activities

\section{Let's get started..}

Discuss the following questions in your groups:

As you work through Semester 2, how would you describe your levels of motivation? Are you always highly motivated? Has anything changed during the year?

Levels of motivation are lower than they should be. Everyone is working hard but not managing to keep on top of everything.

Hard to be as motivated with online lessons and to revise for tests where we have our notes in front of us.

During the foundation year has your level of motivation varied, and if so, what are the likely triggers for that variation?

Everyone's level of motivation at some point in the course has dropped. General triggers would be being overwhelmed in lots of work, falling behind in content .

Varies depending on if we have in-persons or not. Without in persons / struggle sticking to a proper schedule. However sometimes I like the fact that I can do a lot of work on the first part of the week and then less at the end. (more flexible)

Looking ahead, how will you maintain high levels of motivation in order to achieve your ambitions? Set goals and try to look at materials relevant to the course that we find interesting to keep interested in the course as a whole 